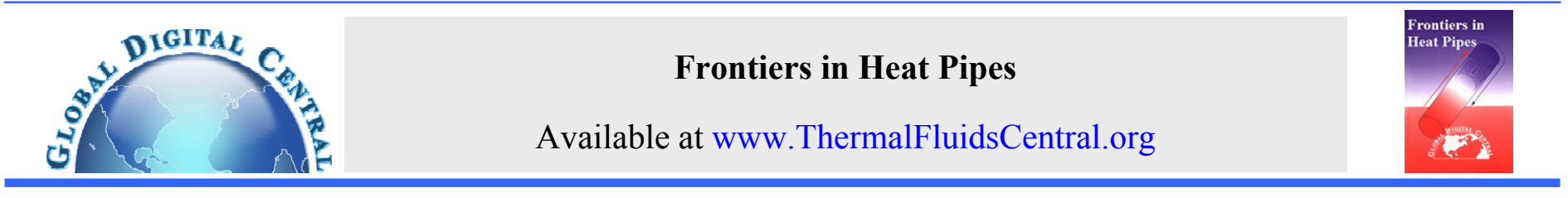

\title{
ADVANCES IN BIPOROUS WICK DESIGN AND TESTING FOR THERMAL GROUND PLANES
}

\author{
Sean Reilly, Ladan Amouzegar, Ivan Catton* \\ University of California at Los Angeles, Los Angeles, CA, 90095, USA
}

\begin{abstract}
Investigation of bi-porous wicks has yielded an effective method for increasing surface heat transfer when the heat flux is high. Tests at UCLA have been aimed at augmenting biporous wicks in an effort to maximize their performance in thermal ground plane devices (TGP). The researchers have developed methods to more closely simulate the working environment inside of a TGP as well as added a monoporous layer between the biporous wick and the heater interface. In this work, it will be shown that both these assertions have been proven experimentally.

Keywords: Three Thermal Ground Plane, Biporous Wicks, Sintered Copper Wicks
\end{abstract}

\section{INTRODUCTION}

The objective of this work is to develop an improved heat spreader by taking advantage of the latent heat absorbed in a phase change process. Previous works have shown that using biporous media as a substrate for boiling have yielded improved performance. A biporous wick is a porous media with two distinct size distribution of pores; small pores provide capillary pumping power and larger pores provide an escape path for vapor (shown schematically in Figure 2). These wicks are intended to eventually be used as the substrate in a Thermal Ground Plane (TGP) device which will function as the heat spreader. This problem is relevant because we can apply these design principles to improve the efficiency of phase change devices by minimizing the superheat required to transfer energy. This can also lead to better tuning of heat pipes for specific circumstances. The difficulty in solving this problem is the complex interplay of all the parameters involved in the system. In this case we are looking at a copper, biporous wick with a layer of copper (monoporous) particles underneath. With the help of Advanced Cooling Technologies Inc. (ACT, who are aiding in the production of these wicks), we are seeking to optimize their performance.

The idea of adding a layer of monoporous particles beneath a biporous layer (henceforth referred to as a "double layer wick") was first suggested by Seminic (2007). It was believed that this would aid in the supply of liquid to the heater interface and delay dry out at the wall. This is due to the high capillary pressure inside the monoporous layer. In this work, a monoporous layer of approximately two particle diameters thick is added in order to investigate this phenomenon.

Previous experiments done with "double layer wicks" were performed without limiting the vapor flow coming out of the wick. The motivation for the insertion of a so-called "restrictor plate", is to demonstrate that the vapor chamber testing performed at UCLA can be an accurate predictor of evaporator performance of the wick as it would perform in an actual device. We will investigate the effect of using various restrictor distances in order to better understand the role vapor restriction plays in performance defined in terms of added temperature drop.
An electric analogue, see Table 1, will be employed to compare the experimental results of the different esperimental configurations used at UCLA and ACT. The analogy is based on the similarity between the governing equation of the flow through porous media (e.g. Darcy`s law), and those governing the flow of electricity through conducting material (Ohm`s law).

Table 1: Resistance Analogies

\begin{tabular}{|cc|c|}
\hline \multicolumn{2}{|c|}{$\begin{array}{c}\text { Fluid Flow } \\
\text { (Bi-porous wick) }\end{array}$} & $\begin{array}{c}\text { Flow of Electricity } \\
\text { (Conducting medium) }\end{array}$ \\
\hline Fluid potential & $\Delta p$ & Electric potential $\Delta V$ \\
\hline Fluid discharge & $m$ & Electric current $I$ \\
\hline Hydraulic resistance & $R_{h}=\frac{v \ell}{\kappa A}$ & Electric resistance $R_{e}=\frac{\rho \ell}{A}$ \\
\hline
\end{tabular}

In this work, the effect of the performance augmentation provided by the addition of a monoporous layer to a biporous wick will be demonstrated, the impact of vapor restriction will be quantified and a model based on the electric analogy will be described. In addition, some of the experiments performed at UCLA will be compared to those completed at an industry counterpart, ACT in order to validate wick testing at UCLA.

\section{WICK CHARACTERISTICS}

A large amount of data was available for double layer wicks leading us to use this type of wick for the present studies. This wick had a particle size of $60 \mu \mathrm{m}$ with a $120 \mu \mathrm{m}$ thick monoporous layer, an $800 \mu \mathrm{m}$ thick biporous layer with $300 \mu \mathrm{m}$ thick clusters. The overall thickness of the wick was $920 \mu \mathrm{m}$ (biporous plus monoporous layers). The nomenclature used to describe these parameters is "monoporous layer dimensions/Biporous Layer dimensions". The wick mentioned above will appear as "60_120/60_300_800".

\footnotetext{
${ }^{*}$ Corresponding author. Email: Catton@ucla.edu.
} 
From previous measurements by Seminic (2007), it is known that the average porosities for the monoporous layer is approximately 0.277 and for the biporous layer is 0.642 . The pore size distributions range from 3-9 $\mu \mathrm{m}$ for the monoporous layer and 30-100 $\mu \mathrm{m}$ for the biporous layer. A schematic of a heat transfer regime map for biporous media can be seen in Figure 1. This figure shows how the wall heat flux is a function of the wall superheat temperature. Note that, in the schematics below, no monoporous layer of particles is shown.

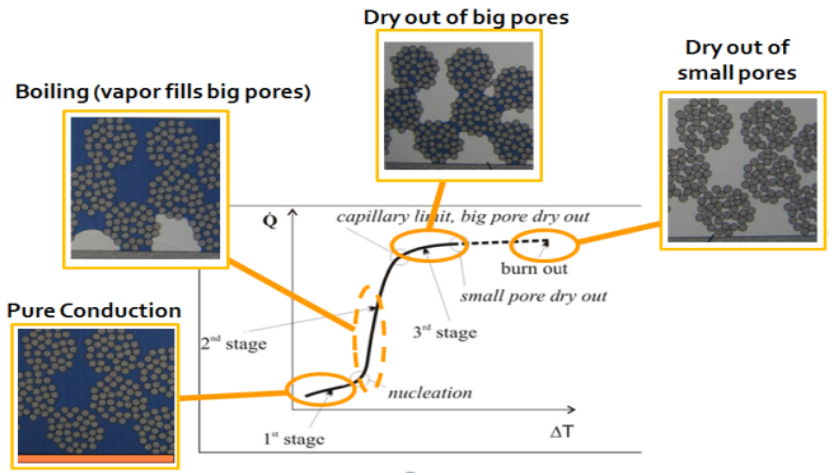

Figure 1: Heat transfer regime map for Biporous Media

Figure 2 is the schematic showing how vapor and liquid interact in the various layers of the bi-layer (or "double layer") wick. Figure 3 shows where the restrictor plate is placed relative to the wick and how the variation of this parameter affects vapor escaping from the wick.

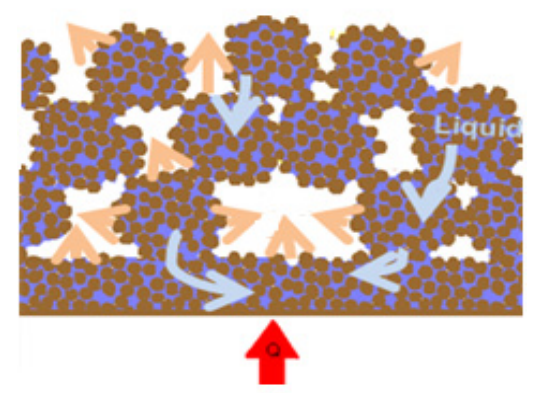

Biporous Layer

Monolayer

Figure 2: Schematic of a double layer wick

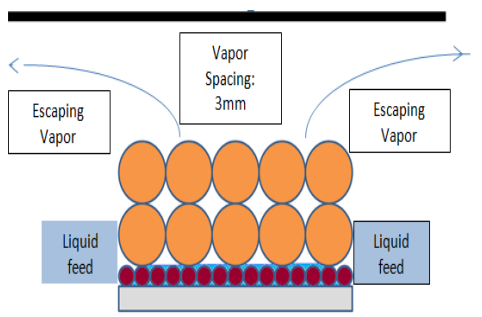

Figure 3: Schematic of Vapor Restriction

From the electric analogue perspective, the open space configuration can be represented as a hydraulic resistance for the vapor discharge in the vertical direction between regions (nodes) 1 and 2 as showed in Figure 4. As in the restricted case, the vapor from the evaporator surface is transported through the vapor space between the restrictor and wick surface and/or the macro-pores inside the bi-porous wick itself. Both of these so called hydraulic resistors are restricting the vapor flow in the radial direction of the wick and they are assumed to both have the same potential difference $\left(\mathrm{P}_{2}-\mathrm{P}_{3}\right)$. The resistance $\mathrm{R}_{2}$ is the equivalent for these two "parallel" resistors between regions 2 and 3 as showed in Figure 4.

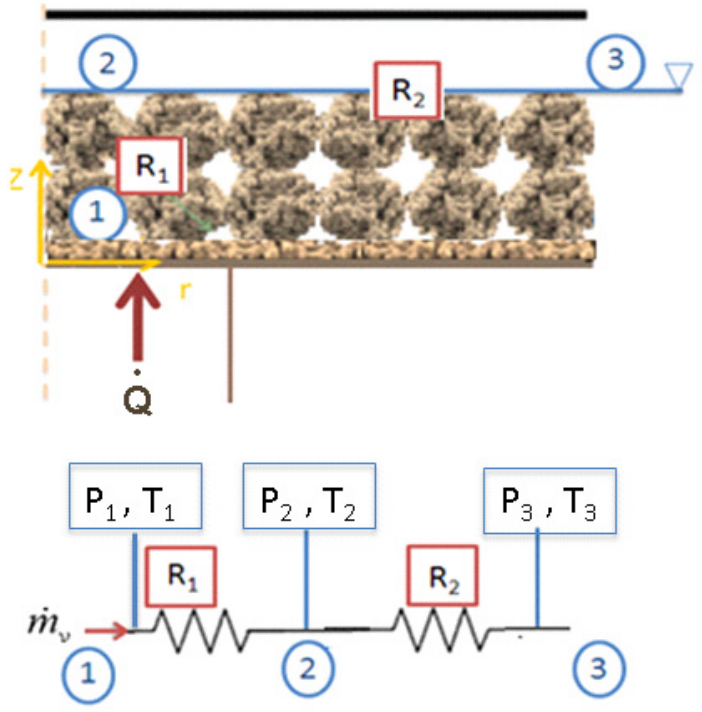

Figure 4: Electrical Analogy for the biporous Wick

It should be noted that the vapor hydraulic resistance across the network is inversely proportional to the vapor permeability through the wick. The permeability is a function of the moisture content of the wick which varies with the heat flux. Hence, the vapor hydraulic resistance is assumed to be a function of heat flux only. In general, the small pores in the clusters provide the necessary capillary pressure needed to pump fluid through the medium. The larger pores provide nucleation sites within the wick.

\section{Experimental Method}

The wick was sintered at ACT to requested specifications before testing. The sample (with wick attached) was prepared for testing by first attaching 13 thermocouples to allow calculation of the heat flux into the wick as well as radial losses across the wick's lower surface. The thermocouples marked "TS" were placed on the outer ring of the collar of the sample and the ones marked "TC" were placed around the perimeter of the neck, or stem, of the sample. The thermocouples marked T1-T5 were placed into pre-drilled holes in the neck of the sample with $\mathrm{T} 1$ being the highest point and T5 is the hole closest to the base of the sample/heater block.

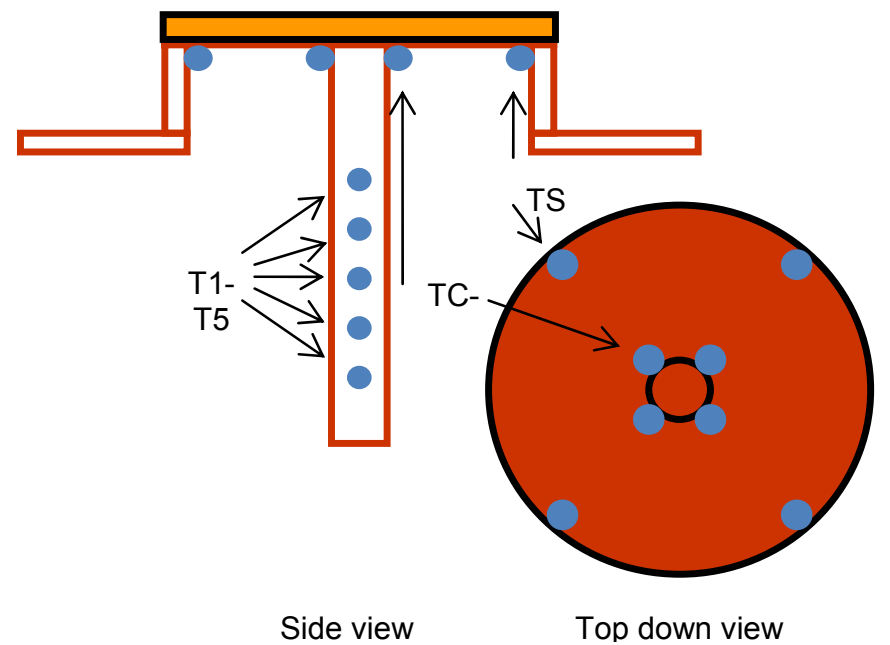

Figure 5: Boiling Target Sample

The wick to be tested was placed inside the boiling chamber shown in Figure 6; which was then closed, evacuated, and charged with working fluid until the wick was covered with a thin layer of fluid. 
Heat was supplied to the wick with three $750 \mathrm{~W}$ cartridge heaters embedded in a block of copper labeled "heater" in Figure 6. This block was soldered to the base of the sample and conducted heat from the heater into the sample and wick.

The next stage of preparation was for saturating the wick with fluid and removing all the air from the wick and the chamber. The heater was set to a medium heat flux (below dry out) and allowed to run for approximately one hour. Water vapor was removed from the chamber using a vacuum pump until the water level was below the top surface of the wick but contacted the sides of the sample. The pressure was reduced to about 0.08 bar within the chamber so that most of the air was removed from the chamber. At this point the heater and vacuum pump were deactivated and the chamber and sample were allowed to cool while sealed in a vacuum. The water supplied to the cooling coil was set to $(40 \pm 0.5) \mathrm{C}$ and kept constant during the experiment. When the chamber cooled, a check was performed to ensure the thermocouple inside the chamber read close to the wall temperature (temperature under the wick to $\pm 0.1^{\circ} \mathrm{C}$ ) so it could be assumed that an insignificant amount of air remains in the chamber. The vapor pressure of the water under these conditions was taken to be approximately 0.08 atmospheres.

Once the sample was adequately saturated, the vapor restrictor plate was inserted. Since the plate makes it impossible to tell how much water has evacuated from the wick and removed from the chamber by the vacuum pump, we had to saturate the wick without the plate present. The chamber was then quickly pressurized and the plate inserted above the wick, and the chamber was re-evacuated back to a high vacuum state. Care was taken so that this process was performed as quickly as possible to reduce air from entering the saturated wick.

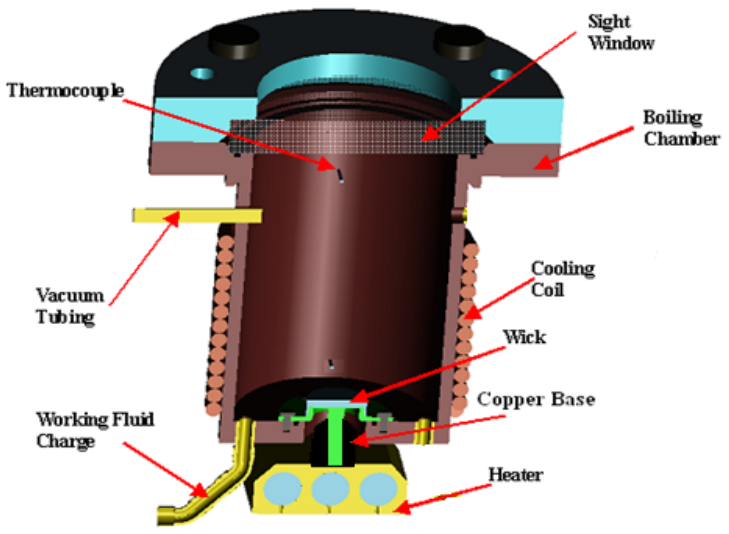

Figure 6: Boiling Target Test Chamber

With the restrictor plate inserted, the experiment is ready to be performed. The heater was reactivated and the heat being supplied to the heater was gradually increased. Data was taken at several steady state power levels, increasing the power until the heaters could no longer safely provide heat flux to the experiment. Steady state was achieved in about 20 minutes. Temperatures were recorded continuously throughout the experiment, but the data collection program noted when the experiment had entered steady state. Steady state was taken to be when the temperature within the stem of the sample did not change by more than $\pm 1^{\circ} \mathrm{C}$ for five minutes. Temperatures T1 through T4 (see Fig. 3) were used in a linear regression model to extrapolate the heat flux from the heaters to the wall/wick interface temperature. Thermocouple readings $T_{\mathrm{C}}$ and $T_{\mathrm{S}}$ were used to estimate radial heat flux inside the copper collar of the boiling target. Radial heat flux losses through the solid copper surface below the wick were calculated using $T_{\mathrm{C}}$ and $T_{\mathrm{S}}$ using a steady conduction equation for a solid disk.

The net heat flux supplied to the heat input region of the wick was calculated by using a linear regression of Fourier's law with the temperature readings $T 1$ through $T 4$ and subtracting the radial heat flux into the collar. To calculate the flux through the stem of the sample, the gradients between each of the thermocouples were calculated and checked for linearity and then averaged to determine the flux. The thermal conductivity of copper was taken to be 401 at $300 \mathrm{~K}$ and 393 at $400 \mathrm{~K}$.

The radial heat flux inside the wick was neglected due to a much lower thermal conductivity of the wick material compared to pure copper (on the order of $20 \mathrm{~W} / \mathrm{m} /{ }^{\circ} \mathrm{K}$ ) as determined by Seminic (2007)). The linearity of the temperatures $T 1-T 4$ was checked at each heat flux to ensure validity of the calculated values. These values were then used in the analysis of the wick performance. Radial heat losses within the base plate were accounted for by a geometric formula suggested by Seminic (2007) which includes the error introduced due to the spacing between $T_{c}$ and $T_{s}$. The average gradients between Tc and Ts were used for the loss calculation to mitigate uncertainties. These losses were subtracted from the heat flux calculated in the stem of the sample before presentation of the data. The equation for the calculation of radial loss is seen below in equation 1 .

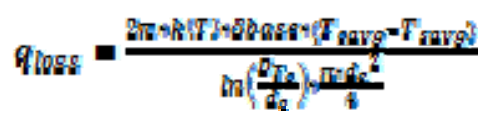

$\mathrm{D}_{\mathrm{Tc}}$ is the diameter for the ring of $\mathrm{T}_{\mathrm{C}}$ measurements, $\delta_{\text {base }}$ is the thickness of the base plate and $d_{e}$ is the diameter of the evaporator. Calculation of thermal conductivity was done by solving a 1D Fourier's equation. We divided the heat flux through the wick by the difference

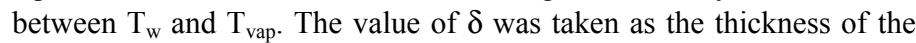
wick plus the vapor space

\section{TGP Testing Method}

The tested TGPs were produced at ACT and are 3" by 5" troughs that are roughly 3 millimeters in depth. On the back side of the trough, a small raised section was added for use as a heater interface. The interface had a small hole in it for the introduction of a thermocouple between the heater and the TGP itself. The trough was filled with the desired wick and then the upper surface was sealed with a plate. Each TGP has two 1 millimeter copper tubes inserted into it. One bisects a corner of the TGP and another is inserted into the middle of the narrow side of the TGP. You can see the layout of the TGP in Figure 6. The corner tube is used in the filling and desiccation process while the tube in the middle of the narrow side is used to insert a thermocouple for measuring the vapor temperature inside the chamber.

Once the TGP was constructed, it was charged with a given amount of fluid based on the porosity of the wick inside the device with some extra in order to help clear the TGP. Once the fluid was injected, the TGP was placed in a special mount that oriented the corner tube straight up and down. The TGP was then heated in order to evaporate excess fluid from the interior of the device as well as purge any air that was left inside. Once the fluid charge was reduced to the desired level (measured by mass) the corner tube was closed off to seal the interior of the chamber.

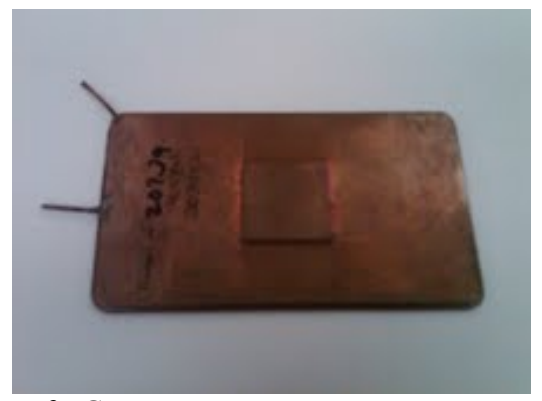

Figure 7: Photo of TGP Layout

For testing, the TGP was placed in a vertical orientation along one if its longer sides with the bottom of the trough perpendicular to the ground. The heater was applied at the back of the TGP on the interface plate 
(seen as the raised section of the TGP above in Figure 7) and a thermocouple was inserted into the hole under the interface plate. A condenser plate was attached on the top of the trough with a network of thermocouples. The entirety of the TGP was coated in insulation before the experiment was started. Once the heater and the cooling plate were activated data was collected at steady state for various heat fluxes.

\section{Experimental Results}

\subsection{Monolayer Addition Testing}

The results presented in Fig. 6 show the results for a double layer wick tested at UCLA. For comparison, data from a single layer biporous wick of $60 \mu \mathrm{m}$ particle size, $300 \mu \mathrm{m}$ cluster size and $800 \mu \mathrm{m}$ thickness is shown on the graph. The double layer sample has a $60 \mu \mathrm{m}$ particle size $120 \mu \mathrm{m}$ thick monolayer underneath the previously mentioned biporous wick, henceforth known as 60_120/60_300_800. It should be noted that the overall thickness of $t$ he double layer wick was $920 \mu \mathrm{m}$ due to the addition of the $120 \mu \mathrm{m}$ thick monolayer.

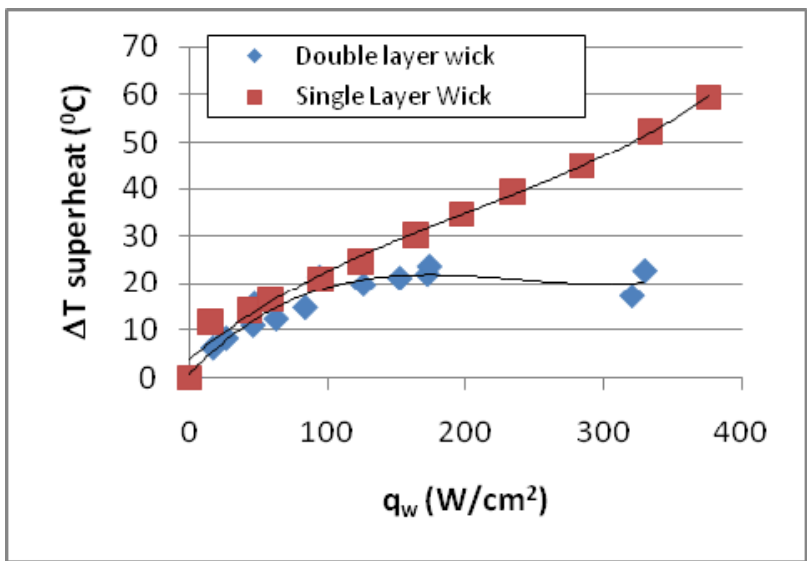

Figure 8: Results of Monolayer addition Testing

As previously stated, the test was performed on a wick with $300 \mu \mathrm{m}$ cluster size and shows clearly that the addition of the monoporous layer to the wick improves the performance of the wicks within the 20-25 degree superheat range. This is because the addition of the monoporous layer reduced the superheat required for a given flux in comparison to a "single layer wick" that is without a monoporous layer. Based on the heat transfer regime map, shown in Fig. 1, it is postulated that once the value of $\Delta \mathrm{T}$ begins to increase with $\mathrm{q}_{\mathrm{w}}$ remaining essentially steady, the start of dry out in the wick has been reached. This heat flux is taken to be the dry out heat flux or $\mathrm{q}_{\mathrm{chf}}$. We are unable to ascertain at this time whether we reached this point in the $300 \mu \mathrm{m}$ case.

A maximum wick effective thermal conductivity, $\mathrm{k}_{\mathrm{eff}}$, value of 171 $\mathrm{W} / \mathrm{m} /{ }^{\circ} \mathrm{K}$ was reached. The effective thermal conductivity was determined using a 1-D Fourier-type calculation, where the wall heat flux was multiplied by the wick thickness and divided by the superheat, $\Delta \mathrm{T}$. This value came at a wall heat flux of $336 \mathrm{~W} / \mathrm{m}^{2}$ which is well below the measured $\mathrm{q}_{\mathrm{chf}}$ for a single layer wick. The initial project goals were to achieve a $\mathrm{k}_{\text {eff }}$ value of over $100 \mathrm{~W} / \mathrm{m} /{ }^{\circ} \mathrm{K}$ with a $\mathrm{q}_{\mathrm{chf}}$ of at least $250 \mathrm{~W} / \mathrm{cm}^{2}$. The heat flux limit was reached before dry out because the current sample design had a neck diameter that was too small. This was done to achieve to achieve greater accuracy in lower heat flux ranges but this makes it difficult to test higher heat fluxes without damaging the heater block.

\subsection{TGP Boiling Chamber Comparison}

The first set of data, see Fig. 8, shows the results of tests performed at UCLA to investigate the effect of the vapor flow restriction on wick performance. It is believed that by restricting the upper surface of the wick we are more closely representing the operating conditions inside of a TGP.

Figure 9 shows that the restriction of vapor flow from the wick increases the super heat required to drive a given heat flux. In general, vapor is produced over the heater in the wick and is expelled upward and out of the wick where it is eventually cooled by the walls of the boiling chamber. In the open case the condenser surface is very large compared to the size of the boiling target sample. In the $0 \mathrm{~mm}$ configuration, vapor has to be forced through the large pores in the wick and out to the condenser. It is postulated that this leads to a pressure drop that is as high as possible within an operational wick.

Even though the $0 \mathrm{~mm}$ case increased the superheat required to drive a given heat flux, increased by 10-12 degrees Celsius in some cases, it is encouraging to note that the wick was still operational in the same region as an unrestricted wick. This helps in the design of the wick because it is known that with a wick of the dimensions tested at UCLA, the wick will not fail due to vapor restriction alone.

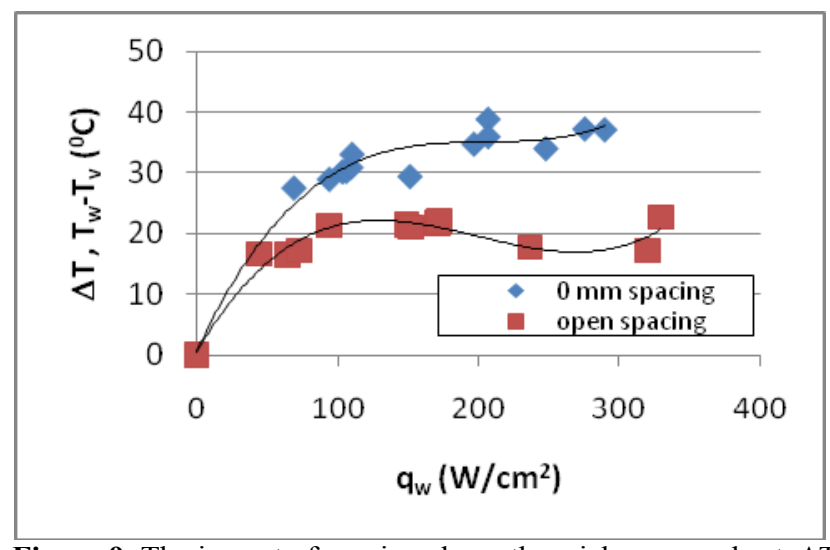

Figure 9: The impact of spacing above the wick on superheat, $\Delta \mathrm{T}$.

In order to compare the experimental data obtained from the UCLA vapor chamber with data from the ACT testing of a TGP, an electrical analog technique was used. The vapor condition (e.g. temperature and pressure) immediately above the wick in the restricted cases was found using the electric analogue analysis. The wick itself can be represented as a hydraulic resistor, R1 which is a function of heat flux only. Hence, the behavior of R1 was initially quantified as a function of current (heat flux) from an analog configuration of the open wick using the experimental data.

The network configuration for the cases in which the open space is restricted would be the resistance R1 and a second resistor R2 in series. The same vapor flow rate is passing through these two resistors as the condensation in the wick is negligible. This also implies that a higher pressure gradient (voltage) is required for the flow. Figure 10 demonstrates that as the heat flux increases the required pressure gradient to maintain the vapor out flow rate increases till the dry-out of the large pores initiates. Since the large pores are considered as the primary vapor passages, when their dry out starts to occur, the vapor permeability increases and the required pressure gradient declines.

The TGP and boiling chambers were treated as thermal circuits and the results were improved such that the two sets of experiments could be compared against each other by taking the wick resistance calculated with each experiment and putting them into the circuit representing the other experiment. This was used this to obtain new wall heat fluxes and then plot them against the original data.

The results for both vapor chamber testing conducted at UCLA and TGP testing conducted at ACT are shown above. The TGP had an approximate spacing of $1 \mathrm{~mm}$. This represents the comparison of the impact of replacing the evaporator resistance from each experiment into the temperature measurements of the other, in order to investigate similarities.

Figure 11 shows that the data for each curve falls very close to each other indicating that with the resistance of the wicks in either case 
are very similar. It should be noted that while comparing the TGP with open space to the boiling chamber test with no open space is conservative, it is difficult to verify that the spacing above the wick is exactly the same as it is in the TGP due to experimental limitations. For this reason, the $0 \mathrm{~mm}$ data was deemed the most accuarte and that is why it is used for comparison.

Figure 12 shows that if we interchange boiling chamber wick resistances in the thermal circuits for the TGP, more variance is observed than in the previous case. This is likely due to the fact that the evaporator resistance calculated using UCLA's boiling chamber data does not express a minima that is expressed in the TGP data. This is because the UCLA tests were not run up to as high a heat flux as the TGP tests. Overall, however, there is agreeable similarity.

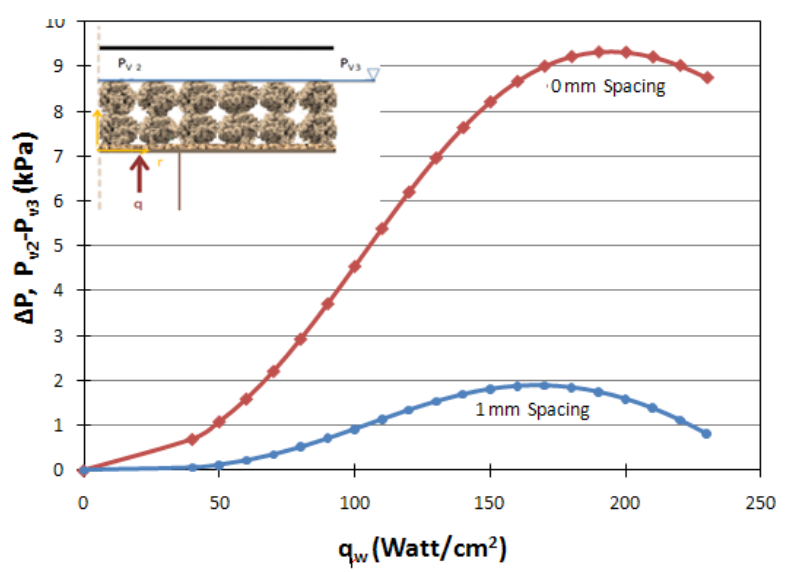

Figure 10: A comparison of the pressure drop with a $1 \mathrm{~mm}$ spacing with a fully restricted case.

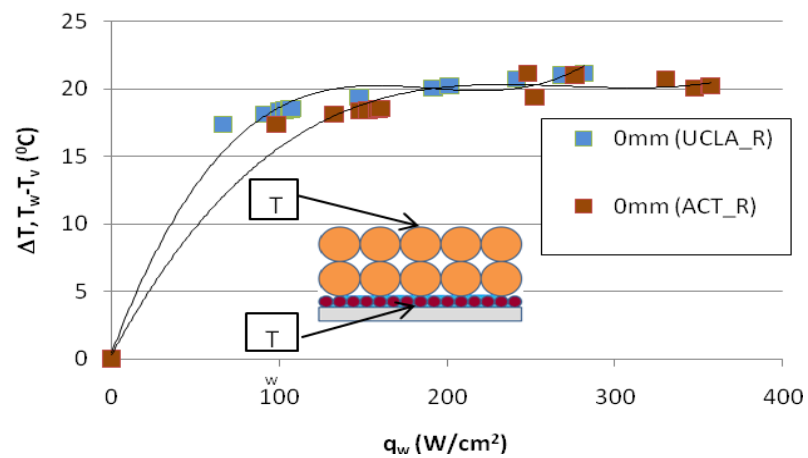

Figure 11: Comparison of ACT and UCLA values of the derived $\triangle T$ for 60_120/60_300_800, at $0 \mathrm{~mm}$ restriction

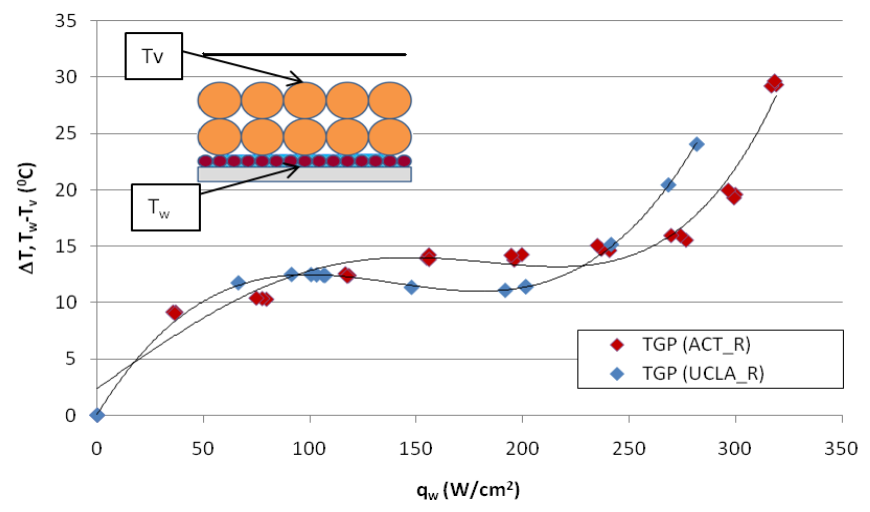

Figure 12 Comparison of ACT and UCLA values of the derived $\triangle \mathrm{T}$ for 60_120/60_300_800, at $1 \mathrm{~mm}$ restriction
Variances could also be the result of differences in the general testing methods between the two experiments. At ACT, the fluid charge inside the TGP is closely regulated as it is well known that fluid charge has a significant impact on heat pipe performance. Empirically this has proven to be true true with the TGP's constructed at ACT. However, at UCLA the fluid reservoir surrounding the boiling target sample is very large relative to the TGP case. Also, when testing for a restricted case at UCLA, some air could enter the wick when the restrictor plate is introduced into the experiment. This is because the wick clearing process requires that the experimenter observe the fluid level inside the chamber, which is impossible to do accurately if the plate is already in the chamber. So, after the wick has been cleared, the chamber must be breifly repressurized in order to insert the plate. While care is taken to make sure this is done quickly and efficiently, some error could be introduced.

Experiments involving the vapor restrictor wick have been repeated various times with several different wicks. In general, the trend that decreasing the available vapor space above the wick increases the superheat required to drive a particular heat flux remains prevalent. Successive tests have shown that data points collected in separate experiments fall within temperature measurement uncertainties. However, in general, over time the performance of the wick tends to degrade. It is postulated that this is due to repeated exposures to air which could be oxidizing the wick and reducing the liquid permeability which is the focus of ongoing work.

\section{Uncertainty Analysis}

Temperatures were acquired when they were at steady state. This was taken to be when the variation of the temperatures was less than $1 \mathrm{deg}$ $\mathrm{C}$ over the course of 5 minutes. This process took around 20 minutes each time the power was varied. Linearity of the readings in the neck (T1-T4) varied between 0.90 and 0.99 . Temperature differences T1-T2, T2-T3, T3-T4 differed by less than $10 \%$ at low heat fluxes but generally became equal as heat flux was increased. Approximately $90 \%$ of the heat provided by the heater was absorbed by the sample and from this approximately $70-80 \%$ reached the evaporator surface. The remainder was conducted into the collar of the sample. Radial loses were calculated individually for each case. Total error in measuring net heat fluxes was estimated to be about $5 \%$ due mostly to the radial heat losses. It is estimated that during the experiments, approximately $1 \%$ of the air originally in the chamber remained in the chamber for the duration of the test. This is evidenced by small variations between the vapor temperature measured and the predicted saturation temperature at the pressures recorded for the interior of the test chamber. The most variation in these values was observed at low heat fluxes.

\section{Conclusions}

It is clear that several advances have been made in the design and testing of biporous wicks for use in phase change heat transfer. First, the addition of a monoporous layer underneath the biporous wick improves its performance. Delaying dry out at the wick interface permits the use of these devices at lower temperatures at the same heat flux as previous biporous designs. This can translate to using smaller TGP devices which could conserve weight and cost in critical systems.

Secondly, as a side benefit of the restrictor testing, it is now known that while having available clear space above the wick is helpful in improving performance, it is not entirely necessary. When looking at the performance of double layer wicks with $0 \mathrm{~mm}$ spacing, a cost is incurred in both pressure drop and superheat but the lack of vapor space will not cause device failure on its own. The device can, however, be made much thinner than was thought possible.

Lastly, the electrical analogue technique has proved useful in comparison between Vapor Chamber testing with actual TGP device testing. While fully operational TGP's are the end product, being able to rapidly test wick geometries and have confidence in their performance considerably reduces the cost and time to investigate 
various device layouts. The data presented in this work shows that idea of the vapor chamber as an accurate predictor of TGP performance is valid. Furthermore, it will aid the researchers in further development of phenomenological models of porous media performance.

\section{ACKNOWLEDGEMENTS}

We would like to acknowledge the support for this work under DARPA BAA07-36 Thermal Ground Plane (TGP). In particular we would like to acknowledge the support of our program manager, Dr. Tom Kenny.

The views, opinions, and/or findings contained in this article/presentation are those of the author/presenter and should not be interpreted as representing the official views or policies, either expressed or implied, of the Defense Advanced Research Projects Agency or the Department of Defense. The views, opinions, and/or findings contained in this article/presentation are those of the author/presenter and should not be interpreted as representing the official views or policies, either expressed or implied, of the Defense Advanced Research Projects Agency or the Department of Defense.

\section{NOMENCLATURE}

$D \quad$ cluster Size, biporous Material $(\mu \mathrm{m})$

$d \quad$ particle size, porous material $(\mu \mathrm{m})$

$k \quad$ thermal conductivity $(\mathrm{W} / \mathrm{m} \cdot \mathrm{K})$

$q \quad$ heat flux $\left(\mathrm{W} / \mathrm{cm}^{2}\right)$

$T \quad$ temperature $(\mathrm{K})$

Greek Symbols

$\delta \quad$ thickness of porous material $(\mu \mathrm{m})$

$\Delta T \quad$ surface super heat $\mathrm{T}_{\mathrm{w}}-\mathrm{T}_{\mathrm{v}}\left({ }^{\circ} \mathrm{K}\right)$

$\begin{array}{ll}\text { Subscripts } & \\ \text { eff } & \text { effective } \\ c h f & \text { critical heat flux } \\ w & \text { wall } \\ v & \text { vapor } \\ c & \text { center area of boiling target } \\ s & \text { outer area of boiling target }\end{array}$

\section{REFERENCES}

Duval F., Fichot F., Quintard M. 2004, "A local thermal nonequilibrium model for two-phase flow with phase-change in porous media". International Journal of Heat and Mass Transfer 47 (2006) 613-
639

doi:10.1016/j.ijheatmasstransfer.2003.07.005

Hanlon M.A. Ma H.B., 2003. "Evaporation Heat Transfer in Sintered Porous Media". Journal of Heat Transfer, Vol. 125, pp. 644-652 doi:10.1115/1.1560145

Hartenstine, J. Bonner R Montgomery J. Semenic T., "Loop thermosyphon design for cooling of large, high heat flux sources". Proceedings of ASME IPACK2007 (2007) IPACK2007-33993

Kovalev S.A. 1987. "Liquid boiling on porous surfaces". HEAT TRANSFER - Soviet Research, Vol. 19, No. 3 May-June 1987

Liter S. Kaviany M. 2001. "Pool boiling CHF enhancement by modulated porous layer coating: theory and experiment". International Journal of Heat and Mass Transfer 44(2001) 4287-4311 doi:10.1016/S0017-9310(01)00084-9

Miscevic M. Rahli O. Tadrist L. Topin F., "Experiments on flows, boiling and heat transfer in porous media: Emphasis on bottom injection". Nuclear Engineering and Design 236 (2006) 2084-2103 doi:10.1016/j.nucengdes.2006.03.034

Semenic T.Catton I., 2005. "Use of biporous wicks to remove high heat fluxes". Applied Thermal Engineering 28 (2008) 278-283

doi:10.1016/j.applthermaleng.2006.02.030

Udell K. S., 1983. "Heat Transfer in porous media considering the phase change and capillarity - the heat pipe effect". International Journal of Heat Mass Transfer Vol. 28, No. 2 485-495 doi:10.1016/0017-9310(85)90082-1

Wang J. and Catton I., 2001. "Biporous heat pipes for high power electronic device cooling" Seventeenth IEEE SEMI-THERM Symposium

Wang J. and Catton I., 2001. "Evaporation heat transfer in thin biporous media". Heat and Mass Transfer 37 (2001) 275-281 doi: $10.1007 / \mathrm{s} 002310000138$

Wasekar V.M Manglik R., 2005. "Pool Boiling heat Transfer in Aqueous Solutions of an Anionic Surfactant". Journal of Heat Transfer Vol. 122 708-715

doi: $10.1115 / 1.1316785$ 